\title{
FAKTOR YANG MEMPENGARUHI PERILAKU MEMBUANG SAMPAH DI SUNGAI SAGO PEKANBARU
}

\author{
Suryani $^{1)}$, Kursiah Warti Ningsih ${ }^{2)}$ \\ ${ }^{1,2}$ Dosen Ilmu Kesehatan Masyarakat STIKes Payung Negeri Pekanbaru, Jl. Tamtama \\ No.6, Labuh Baru Pekanbaru \\ Email : suryaniwibowo@gmail.com
}

Diterima : September 2018, Diterbitkan : Desember 2018

\begin{abstract}
Abstrak
Laporan Direktorat Jenderal Pengendalian Pencemaran dan Kerusakan Lingkungan Kementrian Lingkungan Hidup dan Kehutanan (KLHK), di tahun 2015 hampir 68 persen di 33 provinsi di Indonesia dalam status tercemar berat yang disebbakan oleh limbah rumah tangga. Perilaku masyarakat merupakan penyebab paling besar terhadap kerusakan lingkungan. Tujuan penelitian ini adalah untuk mengetahui faktor manakah yang paling mempengaruhi perilaku membuang sampah rumah tangga di Sungai Sago. Jenis penelitian ini adalah penelitian analitik kuantitatif dengan pendekatan crossectional. Variabel bebas dalam penelitian ini adalah pendidikan, pendapatan, pengetahuan, sarana dan sikap. Populasi pada penelitian ini adalah adalah seluruh ibu rumah tangga yang bertempat tinggal di daerah sekitar sungai Sago yaitu sebanyak 974 orang. Sampel dalam penelitian ini sebanyak 284 orang dan teknik sampling dengan Stratified Random Sampling. Instrumen yang digunakan adalah kuesioner dan lembar observasi. Data primer diperoleh melalui kuesioner dan observasi sedangkan data sekunder dari data kelurahan Sukaramai Pekanbaru. Analisis data menggunakan uji chi square dengan $\alpha=0,05$. Hasil penelitian menunjukkan variable sikap dan sarana mempunyai hubungan sebab akibat dengan perilaku membuang sampah pada masyarakat dengan nilai OR Sikap $(3,270)$ dan Sarana $(3,880)$.keajdian. Variabel pendapatan counfounding terhadap variable sikap. Penelitian ini akan digunakan untuk penelitian selanjutnya yaitu untuk membuat program yang tepat dalam penanggulangan sampah di Sungai Sago Pekanbaru terutama dalam penanggulangan sarana pembuangan sampah.
\end{abstract}

Keyword : Sikap, Perilaku, Sampah, Sungai, Sarana

\begin{abstract}
Report of the Directorate General of Pollution Control and Environmental Damage of Kementrian Lingkungan Hidup dan Kehutanan (KLHK), in 2015 almost 68 percent in 33 provinces in Indonesia were heavily polluted caused by household waste. Community behavior is the biggest cause of environmental damage. The purpose of this study was to determine which factors most influence the behavior of removing household waste on the Sago River. This type of research is quantitative analytical research with a crossectional approach. The independent variables in this study are education, income, knowledge, means and attitudes. The population in this study were all housewives who lived in the area around the Sago River, namely 974 people. The sample in this study were 284 people and the sampling technique was Stratified Random Sampling. The instruments used were questionnaires and observation sheets. Primary data is obtained through questionnaires and observations while secondary data is from data from the Sukaramai village in Pekanbaru. Data analysis using chi square test with $\alpha=0.05$. The results of the study showed that variable attitudes and means had a causal relationship with the behavior of disposing of garbage in the community with OR Attitudes (3,270) and Means (3,880). Counfounding income variable towards attitude variable. This research will be used for further research, namely to make the right program in the handling of waste in the Sago River Pekanbaru, especially in overcoming waste disposal facilities.
\end{abstract}

Keyword: Attitude, Behavior, Trash, River, Means 


\section{PENDAHULUAN}

Menurut Undang-Undang No.18 Tahun 2008, sampah adalah sisa kegiatan seharihari manusia atau proses alam yang berbentuk padat. Dalam pengertian lain sampah adalah segala sesuatu yang tidak dikehendaki oleh yang punya dan bersifat padat, ada yang mudah membusuk terutama terdiri dari zat-zat organik, seperti sisa sayuran, sisa daging, daun dan sebagainya. Sedangkan yang tidak membusuk dapat berupa kertas, plastik, karet, logam, kaca, dan sebagainya. Sampah Rumah tangga adalah sampah yang terdiri dari bahan-bahan padat sebagai hasil kegiatan rumah tangga yang sudah dipakai dan drespondenang, seperti sisa-sisa makanan baik yang sudah dimasak atau belum, bekas pembungkus kertas, plastik, daun, dan sebagainya.

Sampah erat dengan kesehatan masyarakat, karena dari sampah-sampah tersebut akan hidup berbagai mikroorganisme penyebab penyakit (bakteri patogen), dan juga binatang serangga sebagai pemindah atau penyebar penyakit (vektor) (Soekidjo N,2003).

Dinas Kebersihan Kota Pekanbaru mencatat sampah yang dihasilkan oleh penduduk yang berjuimlah sekitar 1,3 juta penduduk kota Pekanbaru adalah 500 ton/hari atau 2,6 kilogram per penduduk setiap harinya. Selama tahun 2016, tercatat kejadian banjir di Pekanbaru dan sekitar Provinsi Riau terjadi karena mulai rusaknya kondisi bantara sungai. Sementara itu sampah yang dibuang sembarangan oleh jutaan warga Pekanbaru di aliran sungai menjadikan aliran sungai terhambat dan menyebabkan banjir di Kota Pekanbaru. (Dinas Kebersihan Kota Pekanbaru, 2017). Berbagai jenis sampah baik yang degradable atau nondegradable akan tercampur jadi satu dan menimbulkan berbagai masalah seperti pencemaran,baik pencemaran bau, tanah ataupun air. Jika sampah tersebut dibuang ke peraiaran atau ke bantaran sungai terjadilah apa yang dinamakan "Pulau Sampah" dan tak terelakkan bencana banjirpun datang di mana-mana. (Endang Susilowati,2007).

Berdasarkan survey pendahuluan yang dilakukan terhadap 20 responden pada 3 April 2017 di pemukiman dekat DAS Sungai Sago Kelurahan Sukaramai Kota Pekanbaru. Di sekitar sungai Sago terdapat daerah pemukiman penduduk yang padat, selain itu juga terdapat pasar yang merupakan pusat perdagangan di kota Pekanbaru sehingga produksi sampah yang begitu banyak, para pedagang tidak memperhatikan kebersihannya, selain itu beberapa diantara pemukiman tesebut kondisinya terlihat dari kondisi fisiknya, air sungai berwarna keruh, berbau, dan dipenuhi sampah, kondisi tersebut kemungkinan karena perilaku masyarakat di sekitar sungai Sago dalam membuang sampah rumah tangga masih belum benar. Adanya sedimen dari sampah bisa mempercepat pendangkalan dan memungkinkan tersumbatnya sungai, sehingga saluran drainase yang fungsi utamanya mencegah banjir tidak akan mampu lagi menjalankan fungsinya.

Tujuan penelitian ini adalah untuk Mengetahui faktor apa yang paling mempengaruhi perilaku masyarakat dalam membuang samapah rumah tangga di sungai Sago.

\section{METODE PENELITIAN}

Jenis penelitian yang dilakukan adalah penelitian analitik kuantiatif dengan pendekatan Cross Sectionall. Pada studi Cross Sectional dimana subjek diobservasi sekali saja melalui pengukuran dan pengamatan pada variable saat yang bersamaan dengan tujuan untuk melihat variabel bebas (independent) dan variabel terikat (dependent) yang dilakukan pada saat pengolahan data.

Penelitian ini dilakukan di Kelurahan Sukaramai yaitu pemukiman yang berada di sekitar Sungai Sago Kota Pekanbaru. Penelitian ini akan di rencanakan selama 
kurang lebih 1 tahun (12 bulan) dan akan di mulai setelah ditandatanganinya kontrak penelitian.

Populasi pada penelitian ini adalah adalah seluruh ibu rumah tangga yang bertempat tinggal di daerah sekitar sungai Sago yaitu Kelurahan Sukaramai Pekanbaru yaitu sebanyak 974 orang. Sampel dalam penelitian ini sebanyak 284 orang. Teknik penarikan sampel yang akan digunakan pada penelitian ini adalah Stratified Random Sampling.

Dalam penelitian ini instrumen yang digunakan adalah Kuesioner,digunakan untuk mengetahui data tentang pengetahuan dan perilakunya dalam membuang sampah rumah tangga di Sungai. Analisa data disesuaikan dengan variabel yang akan diuji. Adapun analisa yang digunakan adalah analisa multivariat

\section{HASIL DAN PEMBAHASAN}

\section{A. HASIL}

Tahap awal analisis multivariat adalah penentuan variabel independen potensial (variabel kandidat multivariat) yang akan masuk dalam analisis multivariat, yaitu variabel dari hasil analisis bivariat yang mempunyai nilaip $<0,25$. Analisis multivariat yang digunakan adalah uji regresi logistic ganda model prediksi ( Hastono, 2007).

Tabel 1 Hasil Seleksi Analisis Bivariat

\begin{tabular}{|c|c|c|c|}
\hline No & Variabel & Pvalue & Keterangan \\
\hline 1 & Pendidikan & 0,323 & $\begin{array}{c}\text { Bukan } \\
\text { Kandidat }\end{array}$ \\
\hline 2 & Pendapatan & 0,071 & Kandidat \\
\hline 3 & Pengetahuan & 0,326 & $\begin{array}{c}\text { Bukan } \\
\text { Kandidat }\end{array}$ \\
\hline 4 & Sika & 0,031 & Kandidat \\
\hline 5 & Sarana & 0,029 & Kandidat \\
\hline
\end{tabular}

Sumber: Data Primer

Dari Tabel 1 dapat dilihat bahwa variabel pendidikan dan pengetahuan mempunyai nilai $\mathrm{p}>0,25$, maka dalam analisis multivariat variabel yang dimasukkan kedalam pemodelan adalah variable pendapatan, sikap dan sarana.

Tabel 2 Pemodelan Multivariat I

\begin{tabular}{clrr}
\hline No & Variabel & Pvalue & OR \\
& & & \\
\hline 1 & Pendapatan & 0,089 & 2.388 \\
2 & Sikap & 0,007 & 3.270 \\
3 & Sarana & 0,011 & 3.880 \\
\hline
\end{tabular}

Sumber: Data Primer

Pada Tabel 2 didapatkan variable pendapatan yang nilai $p$ nya $>0,05$. Variabel dengan nilai $p>0,05$ dikeluarkan dari model multivariat dimulai dari nilai $\mathrm{p}$ terbesar.

Tabel 3 Pemodelan Multivariat II

\begin{tabular}{clcl}
\hline No & Variabel & Pvalue & OR \\
& & \\
\hline $\mathbf{1}$ & Sikap & 0,004 & 3,541 \\
$\mathbf{2}$ & Sarana & 0,001 & 6,525 \\
\hline
\end{tabular}

Sumber: Data Primer

Setelah dilakukan pemodelan kedua, selanjutnya dilihat perubahan nilai $O R$ (OR sebelum variabel X dikeluarkan OR setelah variabel $\mathrm{X}$ dikeluarkan / OR sebelum variabel $\mathrm{X}$ dikeluarkan $\mathrm{x} 100 \%$ ) pada variabel independen yang lainnya dengan atau tanpa variabel pendapatan. Perubahan dapat dilihat pada Tabel 13 sebagai berikut :

Tabel 4 Perubahan Nilai OR dengan dan Tanpa Variabel Pendapatan (Model II)

\begin{tabular}{llccc}
\hline No & Variabel & $\begin{array}{c}\text { OR } \\
\text { dengan } \\
\text { variabel } \\
\text { IMT }\end{array}$ & $\begin{array}{c}\text { OR } \\
\text { tanpa } \\
\text { variabel } \\
\text { IMT }\end{array}$ & $\begin{array}{c}\text { Perub } \\
\text { ahan } \\
\text { OR } \\
(\boldsymbol{\%})\end{array}$ \\
\hline $\mathbf{1}$ & Pendapatan & 2.388 & - & - \\
$\mathbf{2}$ & Sikap & 3.270 & 3,541 & 8,2 \\
$\mathbf{3}$ & Sarana & 3.880 & 6,525 & 68,2 \\
\hline
\end{tabular}

Sumber: Data Primer

Dari Tabel 4 terlihat perubahan OR $>10$ $\%$ pada variabel sarana, maka variabel pendapatan tidak jadi dikeluarkan dan tetap dipertahankan dalam model multivariat. Variabel pendapatan 
merupakan counfounding dengan variabel sarana. Selanjutnya variable pendapatan dimasukkan kembali ke dalam permodelan sehingga di dapatkan permodelan multivariate akhir pada tabel 5.

Tabel 5 Pemodelan Multivariat Akhir

\begin{tabular}{clcc}
\hline No & Variabel & Pvalue & OR \\
& & & \\
\hline 1 & Pendapatan & 0,089 & 2.388 \\
2 & Sikap & 0,007 & 3.270 \\
3 & Sarana & 0,011 & 3.880 \\
\hline
\end{tabular}

Sumber: Data Primer

Tabel 5 menunjukkan variable sikap dan sarana mempunyai hubungan sebab akibat dengan perilaku membuang sampah pada masyarakat dengan nilai OR Sikap $(3,270)$ dan Sarana $(3,880)$. Variabel pendapatan counfounding terhadap variable sikap.

\section{B. PEMBAHASAN}

Berdasarkan hasil pengolahan data secara multivariate variable sikap dan sarana mempunyai hubungan sebab akibat dengan perilaku membuang sampah pada masyarakat dengan nilai OR Sikap $(3,270)$ dan Sarana $(3,880)$. Sikap masyarakat ini diperkirakan dipengaruhi oleh tingkat pengetahuan dan kematangan usia. Bagi sebagian responden yang menyatakan tidak setuju terhadap pengolahan sampah ini dipengaruhi oleh karena belum adanya sarana dan prasarana pengangkutan sampah di Kelurahan Sukaramai sehingga sebagian besar masyarakatnya melakukan pembakaran sampah dan sebagian lainnya membuang sampah di tempat pembuangan sampah sekitar wilayah pasar bahkan ke sungai sebagai upaya pengelolaan sampah dan kegiatan warga masyarakat yang melakukan pengelolaan sampah yaitu dengan memilah sampahsampah seperti kaleng atau botol bekas untuk dijual kembali jumlahnya masih sangat sedikit. Sesuai dengan teori yang tertuang, bahwa sarana fisik merupakan faktor yang mempengaruhi kejiwaan seseorang yang tercermin pada praktek dan perilakunya. Menurut L.Green, faktor pendukung perilaku seseorang salah satunya adalah tersedia atau tidaknya fasilitas dan saran kesehatan.

Berdasarkan hasil pengolahan data secara multivariate variable yang menjadi counfounding adalah variabel pendapatan terhadap variabel sarana. Hal ini disebabkan pendapatan akan mempengaruhi kemampuan responden untuk mempersipakan sarana pembungan sampah sehingga variabel pendapatan menjadi counfounding terhadap variabel sarana. Dan variabel yang tidak berhubungan secara signifikan adalah variabel pengetahuan dan pendidikan.

\section{SIMPULAN}

Faktor yang paling mempengaruhi perilaku masyarakat dalam membaung sampah adalah variable sikap dan sarana. Variabel yang menjadi counfounding adalah variabel pendapatan.

\section{UCAPAN TERIMAKASIH}

Dalam pelaksanaan penelitian ini, peneliti mendapatkan banyak bantuan dan pengarahan dari berbagai pihak yang telah membantu dengan ikhlas. Untuk itu, pada kesempatan kali ini peneliti ingin mengucapkan terima kasih yang sebesar besarnya kepada segenap keluarga besar STIKes Payung Negeri Pekanbaru yang memberikan support moril dan materil. Pihak Kelurahan Sukaramai dan masyarakat Sukaramai yang telah bersedia menyempatkan diri untuk menjadi responden peneliti. Rekan Tim dalam penelitian yang membantu terlaksana kegiatan penelitian ini. Ibunda dan ayahanda tercinta yang tiada henti memberikan do'a, kasih sayang, motivasi serta dukungan moril dan materil kepada peneliti untuk menyelesaikan penelitian ini dan kepada seluruh keluarga yang selalu mendo'akan dan memberi semangat 
DAFTAR PUSTAKA

Achmad Djaenadi S, 2000, Ilmu Gizi Untuk Mahasiswa dan Profesi jilid 1,Jakarta: Dian Rakyat

Anonimous, 2016. Membayangkan wujud 130 ribu ton sampah per hari di Indonesia.

http://m.kumparan.com. Mei 2017

Anonimous, 2017. Sampah pekanbaru mencapai 500 ton perhari. http://googleweblight.com 19 mei 201710.06

Azwar, Azrul. 2002. Pengantar Ilmu Kesehatan Lingkungan. Jakarta: Mutiara

Dinas Kesehatan Propinsi Jawa Tengah. 2005. Standar Prosedur Operasional Klinik Sanitasi Untuk Puskesmas. Jakarta: Depkes

Endang Susilowati. 2007. Sampah Masalah dan Solusinya.http://mst.ft.ugm.ac.d /concent/view/66/i/lang.id diakses 9 September 2008

Indan Entjang. 2000. Ilmu kesehatan Anak. Bandung. PT Citra Aditya Bakti

Maritsa R, 2009. Analisis Faktor-Faktor Yang Berhubungan Dengan Perilaku Masyarakat Dalam Membuang Sampah Rumah Tangga Di Sungai Mranggen. Universitas Negeri Semarang

Mukono, 2002, Prinsip - Prinsip Dasar Kesehatan Lingkungan. Surabaya: Universitas Airlangga.

Nationalgeographic Indonesia, 2016. Air sungai di Indonesia tercemar berat.

http://nationalgeographic.co.id

9.4619 mei 2017

Slamet, J.S. 2002. Kesehatan Lingkungan. Yogyakarta : Gadjah Mada University Press.

Soekidjo Notoatmojo, 2003, Ilmu Kesehatan Masyarakat Prinsip -
Prinsip Dasar. Jakarta: Rineka Cipta.

UU No.18 Tahun 2008 tentang Pengelolaan Sampah

Widyadmoko, H dan Sintorini. 2002. Menghindari, Mengolah dan Menyingkirkan Sampah. Jakarta : Abdi Tandur

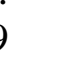

